\title{
Involvement of trehalose in hydrogen sulfide donor sodium hydrosulfide-induced the acquisition of heat tolerance in maize (Zea mays L.) seedlings
}

\author{
Zhong-Guang Li $i^{1,2,3^{*}}$, Li-Ju Luo ${ }^{1,2,3}$ and Li-Ping Zhu $u^{1,2,3}$
}

\begin{abstract}
Background: Trehalose, a non-reducing disaccharide, which involves in the acquisition of various stress tolerance, while hydrogen sulfide $\left(\mathrm{H}_{2} \mathrm{~S}\right)$ is considered as a cell signal molecule, but $\mathrm{H}_{2} \mathrm{~S}$-induced heat tolerance and involvement of trehalose in plants is still unclear.

Results: In present study, pretreatment with hydrogen sulfide donor sodium hydrosulfide (NaHS) markedly increased the accumulation of endogenous $\mathrm{H}_{2} \mathrm{~S}$ in maize seedlings under normal culture conditions, which in turn improved survival percentage of maize seedlings and mitigated increase in electrolyte leakage and malonaldehyde (MDA) accumulation under heat stress. In addition, treatment with NaHS activated increase in the activity of trehalose-6-phosphate phosphatase (TPP) under normal culture conditions, followed by induced the accumulation of endogenous trehalose, but this accumulation was eliminated by addition of sodium citrate, an inhibitor of TPP. During the process of heat stress, maize seedlings treated with NaHS maintained higher TPP activity and trehalose content than those of control. On the other hand, exogenous application of trehalose also increased the content of endogenous trehalose in maize seedlings under normal culture conditions, alleviated increase in electrolyte leakage and MDA accumulation under heat stress, which in turn improved survival percentage of maize seedlings, and the heat tolerance induced by trehalose was enhanced by exogenous supplement of NaHS, but exogenous trehalose treatment had not significant effect on the accumulation of endogenous hydrogen sulfide in maize seedlings.
\end{abstract}

Conclusion: These data suggest that sodium hydrosulfide pretreatment could improve heat tolerance of maize seedlings and this improvement may be involved in trehalose accumulation by activating TPP activity.

Keywords: Heat stress; Heat tolerance; Hydrogen sulfide; Maize (Zea mays L.) seedlings; Trehalose

\section{Background}

Trehalose, a stable non-reducing disaccharide, which is composed of two D-glucopyranose units with an $\alpha, \alpha$ $(1 \rightarrow 1)$ linkage, it can withstand heating at $100^{\circ} \mathrm{C}$ between $\mathrm{pH} 3.5-10$ for $24 \mathrm{~h}$. The $\alpha, \alpha-1,1$ configuration is crucial for the ability of trehalose to preserve lipid bilayer structure in the absence of water (Goddijn and van Dun, 1999; Iordachescu and Imai, 2008; Paul et al., 2008; Fernandez et al., 2010). Trehalose has been shown to efficiently stabilize dehydrated enzymes, proteins and lipid

\footnotetext{
*Correspondence: zhongguang_li@163.com

'School of Life Sciences, Yunnan Normal University, Kunming 650092, PR China

${ }^{2}$ Engineering Research Center of Sustainable Development and Utilization of Biomass Energy, Ministry of Education, Kunming 650092, PR China Full list of author information is available at the end of the article
}

membranes, as well as protect biological structures from damage during desiccation by replacing water. Trehalose forms an amorphous glass structure that limits molecular motion, preventing protein aggregation and scavenging free radical under stress conditions (Goddijn and van Dun, 1999; Benaroudj et al., 2001; Iordachescu and Imai, 2008; Paul et al., 2008; Fernandez et al., 2010). Based on these unique features and functions, trehalose metabolism and signaling turns into an area of emerging significance. Trehalose is found in various organisms, including bacteria, fungi, yeast, algae, insects and some plants (Paul et al., 2008; Fernandez et al., 2010). To date, two pathways of trehalose metabolism were identified: the trehalose-6phosphate synthase/phosphatase (OtsA-OtsB) pathway and the trehalase pathway. The former is used for trehalose synthesis, whereas the latter is proposed to operate in

\section{Springer}


trehalose degradation. In plants, the OtsA-OtsB pathway is the only biosynthesis pathway found. Trehalose 6phosphate synthase (TPS) catalyzes the transfer of glucose from uridine diphosphate glucose (UDPG) to glucose 6phosphate (G6P) to form trehalose 6-phosphate (T6P) and uridine diphosphate (UDP), and trehalose phosphate phosphatase (TPP) dephosphorylates T6P to form trehalose and inorganic phosphate. Trehalase is the key enzyme responsible for the hydrolysis of trehalose (Goddijn and van Dun, 1999; Iordachescu and Imai, 2008; Paul et al., 2008; Fernandez et al., 2010; Zhou et al., 2013). Therefore, the control of TPP and trehalase is key in the accumulation of endogenous trehalose in plants (Paul et al., 2008). In recent years, accumulating evidences showed that trehalose, serving as a signal molecule, plays very important role in plant growth, development and the acquisition of stress tolerance including heat tolerance (Paul et al., 2008; Fernandez et al., 2010). However, interaction of hydrogen sulfide $\left(\mathrm{H}_{2} \mathrm{~S}\right)$ and trehalose in the acquisition of heat tolerance in plants still remains elusive.

Hydrogen sulfide, a colorless gas with a strong odor of rotten eggs, has long been considered as a phytotoxin (Zhang et al., 2010a,b; Chen et al., 2011; Li et al., 2011; Li, 2013). However, in recent years, $\mathrm{H}_{2} \mathrm{~S}$ has been identified as a third endogenous gaseous transmitter after nitric oxide (NO) and carbon monoxide (CO), playing multiple physiological roles in animal systems (Li et al., 2011; Wang, 2012). In plant systems, the positive effect of $\mathrm{H}_{2} \mathrm{~S}$ is being emerged in growth, development, and the acquisition of stress tolerance (García-Mata and Lamattina, 2010; Hancock et al., 2011). Pretreatment with $\mathrm{H}_{2} \mathrm{~S}$ donor NaHS can improve the resistance of plants to osmotic and oxidative stress in sweetpotato (Zhang et al., 2009a) and wheat (Zhang et al., 2011) by increasing the activity of the antioxidant enzymes. In addition, Shan et al. (2011) found that fumigation of spinach increased ascorbic acid and glutathione levels, and it was estimated that approximately $40 \%$ of the $\mathrm{H}_{2} \mathrm{~S}$ was converted to glutathione in the leaves. Also, $\mathrm{H}_{2} \mathrm{~S}$ donor, NaHS or p-(methoxyphenyl) morpholinophosphin-odithioic acid (GYY 4137), can promote seed germination (Zhang et al., 2010b; Li et al., 2012a), root organogenesis (Zhang et al., 2009b), stomata opening (Lisjak et al., 2010), and improve the antioxidative response to heavy metal such as chromium stress (Zhang et al., 2010a). Our previous results also showed that NaHS treatment could improve the resistance of tobacco cells ( $\mathrm{Li}$ et al., 2012b), maize (Li et al., 2013a,b) and wheat seedlings (Wu et al., 2013) to high temperature and drought stress, and the acquisition of this stress tolerance involved in the second messenger such as $\mathrm{Ca}^{2+}$, nitric oxide (NO) and proline accumulation. But in maize seedlings, the mechanisms of $\mathrm{H}_{2} \mathrm{~S}$-induced heat tolerance are not fully clear.

Maize (Zea mays L.) not only is the third most important food grain crop after wheat and rice, but also a new model plant, high temperature is the principal cause of maize failure worldwide, global warming accentuates this problem (Leipner and Stamp, 2009; Strable and Scanlon, 2009). Many studies have showed high temperatures not only lead to direct injuries including protein denaturation and aggregation, increased fluidity of membrane lipids, but also to indirect heat injuries like cell dehydration, inactivation of enzymes, inhibition of protein synthesis and loss of membrane integrity, and eventually result in severe cellular injury and even cell death (Wahid et al., 2007; Hanumappa and Nguyen, 2010).

On the basis of the above-mention evidences, implying interaction between $\mathrm{H}_{2} \mathrm{~S}$ and trehalose may be existed in the acquisition of stress tolerance including heat tolerance, but their interaction in the acquisition of heat tolerance in maize seedlings is unknown. In this study, using maize seedlings as materials, effect of NaHS treatment on heat tolerance and trehalose accumulation, as well as its possible metabolic pathways were investigated, the purpose was to expound interaction between $\mathrm{H}_{2} \mathrm{~S}$ and trehalose in the acquisition of heat tolerance in maize seedlings.

\section{Methods}

\section{Plant material, sodium hydrosulfide pretreatment and} heat tolerance

Commercial variety of maize (Zea mays L., Huidan No. 4) was used in the present experiments. Like numerous previous researchers, NaHS was used as a donor for $\mathrm{H}_{2} \mathrm{~S}$, when $\mathrm{NaHS}$ is dissolved in water, $\mathrm{HS}^{-}$is released and forms $\mathrm{H}_{2} \mathrm{~S}$ with $\mathrm{H}^{+}$(Wang, 2012). The seeds were sterilized in $0.1 \%$ $\mathrm{HgCl}_{2}$ for $10 \mathrm{~min}$, and pre-soaked in distilled water for $12 \mathrm{~h}$ for imbibition. The soaked seeds were sowed on six layers of wetted filter papers in trays $(24 \mathrm{~cm} \times 16 \mathrm{~cm}$, approximately 300 seeds per tray) with covers and germinated at $26^{\circ} \mathrm{C}$ in the dark for $2.5 \mathrm{~d}$. After germination, the seedlings with unanimous growth were irrigated with $100 \mathrm{ml}$ of 0 (control), $0.3,0.6,0.9$ and $1.2 \mathrm{mM}$ sodium hydrosulfide (NaHS) (the pH of the solution was adjusted to 6.0 with $1 \mathrm{M} \mathrm{HCl}$ ), a hydrogen sulfide donor (Lisjak et al., 2013; Wang, 2012; García-Mata and Lamattina, 2013) for $6 \mathrm{~h}$ (pretreatment with NaHS had no significant effect on the growth of seedlings). Afterward, NaHS-treated seedlings in trays with covers were exposed to high temperature at $47^{\circ} \mathrm{C}$ in the dark (70\% RH) for $15 \mathrm{~h}$ for heat stress. At the end of heat stress, electrolyte leakage of roots, MDA content in coleoptiles and survival percentage (\%) were assayed, respectively, according to our previous methods ( $\mathrm{Li}$ et al., $2012 \mathrm{~b})$. One $\mathrm{cm}$ root tips of seedlings were cut off and the percentage of electrolyte leakage from the tips was measured with a conductometer. In addition, the level of lipid peroxidation in coleoptiles of the seedlings was measured in terms of MDA content determined by thiobarbituric acid reaction. Electrolyte leakage and MDA content were expressed as \%, and nmol g ${ }^{-1} \mathrm{FW}$, respectively. 
In addition to electrolyte leakage and MDA content, after heat stress, seedlings were transferred to a climate chamber with $26^{\circ} \mathrm{C}$ and $100 \mu \mathrm{mol} \cdot \mathrm{m}^{-2} \cdot \mathrm{s}^{-1}$ as well as $12 \mathrm{~h}$ photoperiod for a week for recovery and irrigated with $1 / 2$ Hoagland solution daily. Survival percentage (\%) was counted after recovery, and the seedlings that could regrow and become green during recovery were considered to have survived (Li et al., 2013a,b).

\section{Measurement of $\mathrm{H}_{2} \mathrm{~S}$ content}

In order to understand effect of different concentrations of NaHS treatment on endogenous $\mathrm{H}_{2} \mathrm{~S}$ content, $\mathrm{H}_{2} \mathrm{~S}$ content in coleoptiles of the seedlings was determined according to the methods described by Christou et al. (2013) with modifications. Briefly, coleoptiles of maize seedlings ( $1 \mathrm{~g}$ ) were ground into fine powder with a mortar and pestle under liquid nitrogen and then were homogenized in $1 \mathrm{ml}$ of $100 \mathrm{mM}$ potassium phosphate buffer ( $\mathrm{pH}$ 7.0) containing 10 mM EDTA. The homogenate was centrifuged at $15,000 \times g$ for $15 \mathrm{~min}$ at $4^{\circ} \mathrm{C}$ and $200 \mu \mathrm{l}$ of the supernatant was used for the quantification of $\mathrm{H}_{2} \mathrm{~S}$, in an assay mixture containing also $3760 \mu \mathrm{l}$ extraction buffer and $40 \mu \mathrm{l}$ of $20 \mathrm{mM} 5,5^{\prime}$-dithiobis (2-nitrobenzoic acid), in a total volume of $4 \mathrm{ml}$. The assay mixture was incubated at room temperature for $2 \mathrm{~min}$ and the absorbance was read at $412 \mathrm{~nm} . \mathrm{H}_{2} \mathrm{~S}$ was calculated based on a standard curve of known concentrations of $\mathrm{NaHS}$ and expressed as nmol g ${ }^{-1}$ fresh weight (FW).

\section{Measurement of trehalose-6-phosphate phosphatase and trehalase activities}

Trehalose-6-phosphate phosphatase (TPP) and trehalase are key enzymes in trehalose acclimation in plants, the former is used for trehalose biosynthesis, while the latter controls its degradation (Paul et al., 2008). During the process of $0.6 \mathrm{mM} \mathrm{NaHS}$ treatment and heat stress, TPP and trehalase activities in coleoptiles and roots of maize seedlings were measured according to Lunn et al. (2006) and (El-Bashiti et al. 2005). Briefly, the samples of coleoptiles or roots ( $1 \mathrm{~g}$ ) were ground with liquid nitrogen by using mortar and pestle. The powders were then suspended in ice-cold suspension solution containing $0.1 \mathrm{M}$ citrate- $\mathrm{Na}^{+}$, pH 3.7, 1 mM PMSF, 2 mM EDTA and insoluble $1 \%(\mathrm{w} / \mathrm{v})$ polyvinylpyrrolidone. The homogenate was centrifuged at $15,000 \times g$ for $20 \mathrm{~min}$ at $4^{\circ} \mathrm{C}$. The supernatant was used for TPP and trehalase assays .

TPP (TPP, EC 3.1.3.12) activity was determined by following the release of orthophosphate from Trehalose-6phosphate (Tre6P). Reactions containing $1.25 \mathrm{mM}$ Tre6 $\mathrm{P}$ and $8 \mathrm{mM} \mathrm{MgCl}_{2}$ in $25 \mathrm{mM}$ Hepes- $\mathrm{K}^{+}, \mathrm{pH} 7.0$, in a total volume of $300 \mu \mathrm{l}$ were incubated at $30^{\circ} \mathrm{C}$ and stopped by adding $30 \mu \mathrm{l}$ of $2 \mathrm{M}$ trichloroacetic acid. Orthophosphate was measured in samples using the ascorbic acid-ammonium molybdate reagent and TPP activity was expressed as $\mu \mathrm{mol} \mathrm{g}^{-1} \mathrm{FW} \mathrm{min}^{-1}$.

Trehalase (EC 3.2.1.28) activity was determined calorimetrically according to Garg and Chandel (2011) by measuring the glucose released. The reaction mixture contained $50 \mathrm{mM}$ trehalose in $50 \mathrm{mM} \mathrm{MES} / \mathrm{KOH}$ buffer (pH 6.3). After incubation at $30^{\circ} \mathrm{C}$ for $30 \mathrm{~min}$, the reaction was stopped by heating at $100^{\circ} \mathrm{C}$ for $5 \mathrm{~min}$. The glucose released was measured by the dinitrosulfosalicylic acid (DNSA) reagent. The trehalase activity was calculated using a standard curve of glucose and expressed as $\mu \mathrm{mol} \mathrm{g}{ }^{-1}$ FW.

\section{Determination of trehalose content}

To investigate effect of NaHS pretreatment on trehalose content under normal cultural conditions and heat stress, after being treated with solution of $0.6 \mathrm{mM} \mathrm{NaHS}$ alone or in combination with $0.6 \mathrm{mM}$ sodium citrate (a inhibitor of TPP) for $0,3,6$ and $9 \mathrm{~h}$, the accumulation of trehalose in coleoptiles and roots was determined as per the methods of Kumar et al. (2012) as well as Jagdale and Grewal (2003) with modifications. The coleoptiles or roots $(1 \mathrm{~g})$ were homogenized in $5 \mathrm{ml}$ of $80 \%(\mathrm{v} / \mathrm{v})$ hot ethanol and centrifuged at $15,000 \times g$ for $15 \mathrm{~min}$, and the supernatants were transferred to glass tube and dried at $80^{\circ} \mathrm{C}$. After drying, samples were redissolved with $5 \mathrm{ml}$ distilled water as assay solution and used for assays of trehalose. Detailed protocols were described as follow: A $100 \mu \mathrm{l}$ assay solution was mixed with $0.2 \mathrm{~N} \mathrm{H}_{2} \mathrm{SO}_{4}$ and boiled at $100^{\circ} \mathrm{C}$ for $10 \mathrm{~min}$ to hydrolyze any sucrose or glucose-1phosphate etc., and then chilled on ice. A $150 \mu \mathrm{l} 0.6 \mathrm{~N}$ $\mathrm{NaOH}$ was added to above mixture and boiled for $10 \mathrm{~min}$ to destroy reducing sugars, and then chilled again. $2.0 \mathrm{ml}$ of anthrone reagent $(0.05 \mathrm{~g}$ anthrone per $100 \mathrm{ml}$ of $72 \%$ $\mathrm{H}_{2} \mathrm{SO}_{4}$ ) was added and boiled for 10 min to develop a color and then chilled again. Then absorbance measurements were made at $630 \mathrm{~nm}$ with spectrophotometer. The trehalose concentration was calculated using a standard curve and expressed as nmol g $\mathrm{g}^{-1} \mathrm{FW}$.

\section{Trehalose treatment and heat tolerance}

To further study effect of the combination of trehalose and NaHS pretreatment on content of endogenous trehalose and heat tolrance of maize seedlings, 2.5-day-old seedlings were transferred to aqueous solution of 0 (control), 5, 10, 15, 20 and $25 \mathrm{mM}$ trehalose alone in combination with $0.6 \mathrm{mM}$ NaHS for $9 \mathrm{~h}$, and the contents of endogenous trehalose and $\mathrm{H}_{2} \mathrm{~S}$ in coleoptiles was measured as above-mentioned methods, respectively. In addition, seedlings treated with trehalose for $6 \mathrm{~h}$ were subjected to high temperature at $47^{\circ} \mathrm{C}$ for $15 \mathrm{~h}$. Electrolyte leakage of roots, MDA content in coleoptiles and survival percentage were assayed according to above-mentioned methods, respectively. 


\section{Statistical analysis}

The experiment was set up according to a completely randomized design with five replications. The data were processed statistically using software package SPSS version 21.0 (SPSS, Chicago, USA) and the comparison of averages of each treatment was based on the analysis of variance (one-way ANOVA) according to Duncan's multiple range test. Figures were drawn by SigmaPlot 12.0 (Systat Software Inc., London, UK), error bars represent standard error and each data in figure represents the mean \pm SE of at least three independent experiments, asterisk and double asterisks on the bars indicate significant differences $(P<0.05)$ and very significant differences $(P<0.01)$.

\section{Results}

Effect of NaHS treatment on endogenous $\mathrm{H}_{2} \mathrm{~S}$ content under normal culture conditions and heat tolerance in maize seedlings

2.5-day-old maize seedlings was subjected to heat stress at $47^{\circ} \mathrm{C}$ for $15 \mathrm{~h}$ after being treated with 0 (control), 0.3, 0.6, 0.9 and $1.2 \mathrm{mM} \mathrm{NaHS}$ for $6 \mathrm{~h}$. As shown in Figure 1, under normal culture conditions at $26^{\circ} \mathrm{C}$, application of $\mathrm{NaHS}$ with different concentrations, compared with the control without NaHS treatment, improved endogenous $\mathrm{H}_{2} \mathrm{~S}$ content in coleoptiles of maize seedlings, especially in pretreatment with $0.6 \mathrm{mM}$ and above reached very significant difference $(P<0.01$, Figure $1 \mathrm{~A})$, which in turn increased survival percentage of maize seedlings under heat stress at $47^{\circ} \mathrm{C}$, and treatment with $0.6 \mathrm{mM}$ reached very significant difference $(P<0.01$, Figure $1 \mathrm{~B})$, similar to the content of endogenous $\mathrm{H}_{2} \mathrm{~S}$ (Figure $1 \mathrm{~A}$ ), but higher concentration of $\mathrm{NaHS}(\geq 0.9 \mathrm{mM})$ reduced survival percentage (Figure 1B). Higher concentration of NaHS was bad for the acquisition of heat tolerance in seedlings of maize, coinciding with one of the characteristics of other signal molecules such as $\mathrm{Ca}^{2+}$, $\mathrm{NO}$ and $\mathrm{H}_{2} \mathrm{O}_{2}$.

Heat stress damages membrane systems and leads to the leakage of electrolytes from plant cells, whereas MDA content is often used as a measure of lipid peroxidation as a result of reactive oxgen species (Wahid et al., 2007). In present experiments, to understand effect of different concentrations of NaHS treatment on electrolyte leakage and MDA content, which were determined and found that NaHS treatment alleviated increase in electrolyte leakage and MDA content, especially $0.6 \mathrm{mM}$ NaHS treatment showed more significant difference $(P<$ 0.01 , Figure 2), but mitigative effect of higher concentrations of NaHS on heat stress was not obvious, analogous to change in survival percentage (Figure 1B). Therefore, the concentration of $0.6 \mathrm{mM}$ NaHS was used in further experiments. These results illustrated that NaHS-induced heat tolerance of maize seedlings in a concentrationdependent manner may be achieved by accumulating endogenous $\mathrm{H}_{2} \mathrm{~S}$.

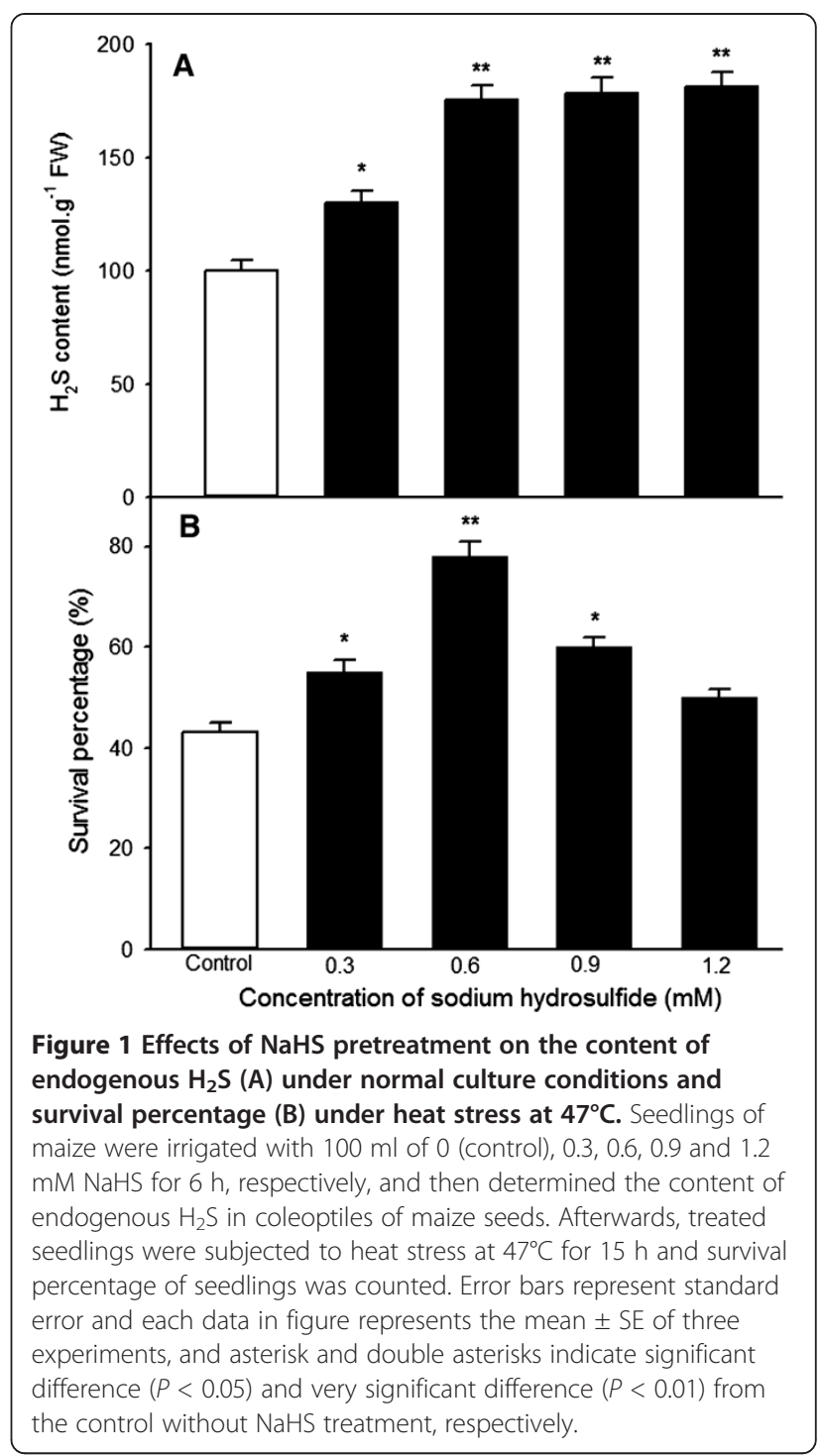

Effect of NaHS on TPP and trehalose activities as well as endogenous trehalose content in maize seedlings

To explore effect of NaHS on TPP and trehalase activity as well as the content of endogenous trehalose, after maize seedlings were treated with $0.6 \mathrm{mM} \mathrm{NaHS}$, the activities of TPP and trehalase as well as the endogenous trehalose content were measured during the course of treatment and heat stress. The data exhibited that pretreatment with NaHS increased the activity of TPP in coleoptiles and roots of maize seedlings under normal cultural conditions, and this improvement increased with the increase of treatment time, 3 and 6 h of treatment reached very significant difference $(P<0.01$, Figure 3$)$ in roots and coleoptiles, respectively, while the activity of trehalase was not obvious from beginning to end (Figure 4). In addition, application of NaHS improved the content of endogenous trehalose in 


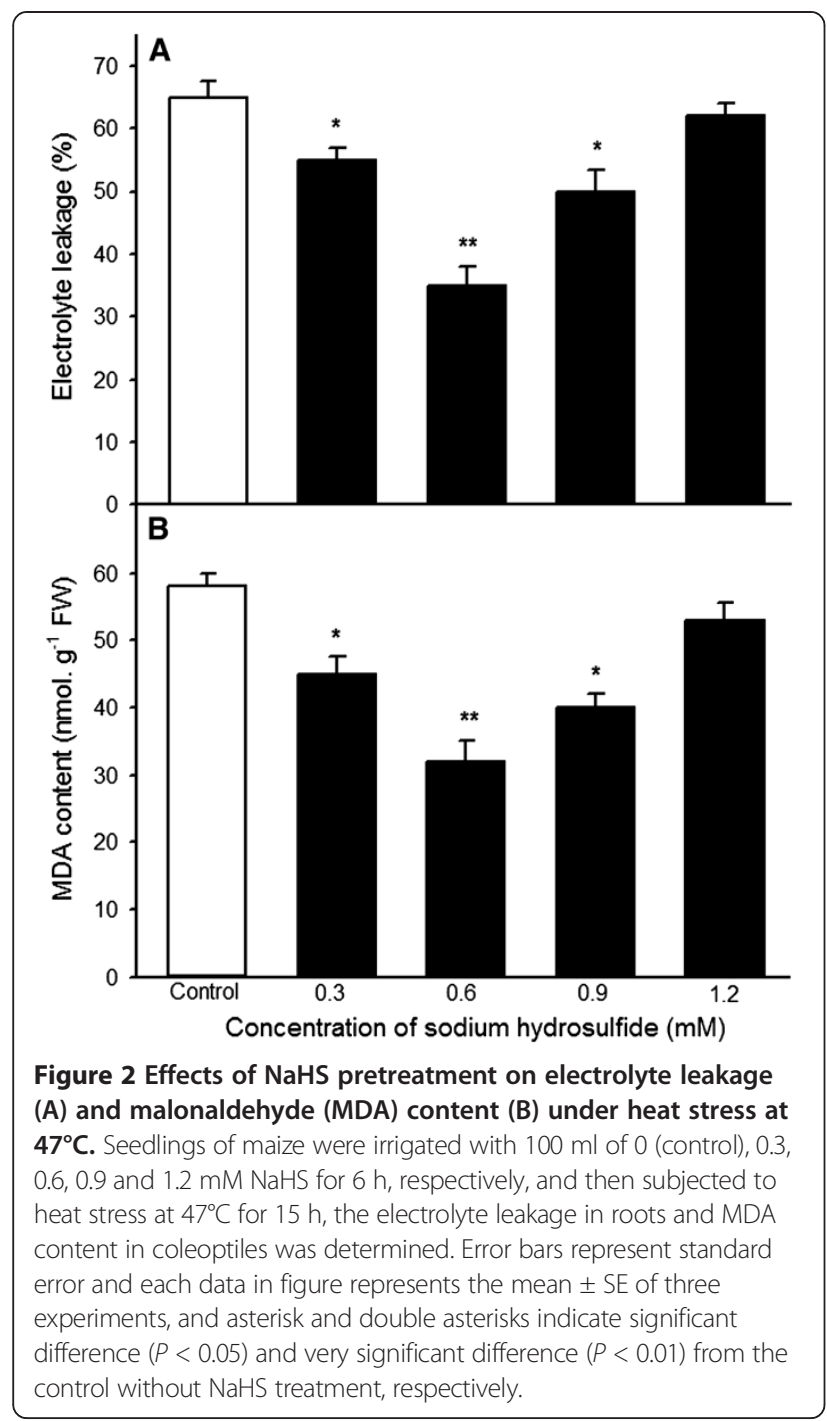

roots and coleoptiles of the seedlings under normal cultural conditions, reaching very significant difference $(P<0.01$, Figure $5 \mathrm{~A})$ at 3 and $6 \mathrm{~h}$ of treatment, respectively, similar to the change in activity of TPP (Figure 3). The speed of trehalose accumulation in roots was more rapid than that of coleoptiles (Figure 5A), reaching very significant difference at $3 \mathrm{~h}$ of treatment in roots, but the amount of trehalose lowered than that of coleoptiles, analogous to the increase in the activity of TPP (Figure 3), while the accumulation of trehalose was eliminated by additon of sodium citrate, an inhibitor of TPP (Figure 5B). By contrast, during the process of heat stress, there was a trend toward decrease in TPP and trehalase activity as well as trehalose content in control and treated maize seedlings, but seedlings treated $0.6 \mathrm{mM}$ NaHS maintained higher enzymes activities and trehalose content than those of control from beginning to end (Figures 3, 4 and 5). These results showed that

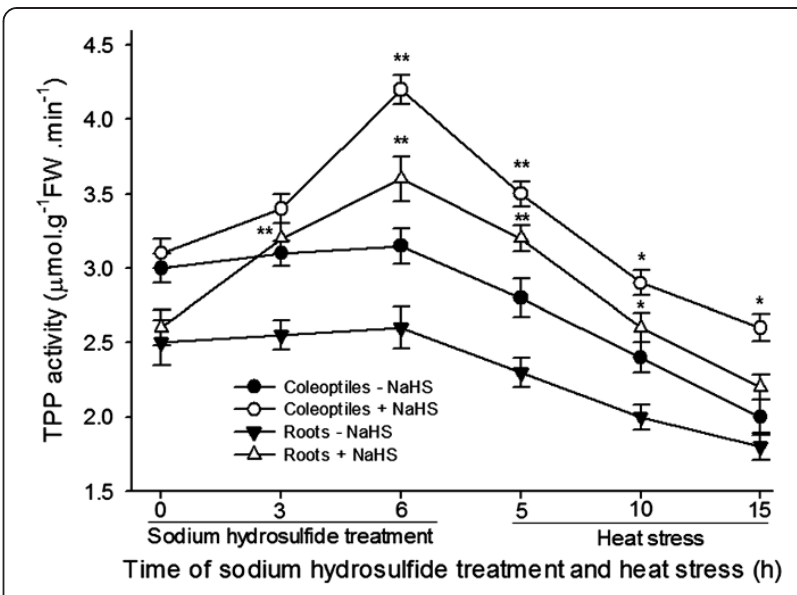

Figure 3 Effects of NaHS pretreatment on the activity of trehalose 6-phosphate phosphatase (TPP) in coleoptiles and roots of maize seedlings under normal culture conditions and heat stress. Seedlings of maize were irrigated with $100 \mathrm{ml}$ of $0.6 \mathrm{mM} \mathrm{NaHS}$ for $6 \mathrm{~h}$, and then transferred to heat stress, during the treatment and heat stress, TPP activity in both coleoptiles and roots was determined. Error bars represent standard error and each data in figure represents the mean \pm SE of three experiments, and asterisk and double asterisks indicate significant difference $(P<0.05)$ and very significant difference $(P<0.01)$ from the control without NaHS treatment, respectively.

pretreatment with NaHS could improve the content of endogenous trehalose under normal cultural conditions and alleviated decrease in its content under heat stress in maize seedlings, and this improvement and alleviation may be achieved by activating TPP activity.

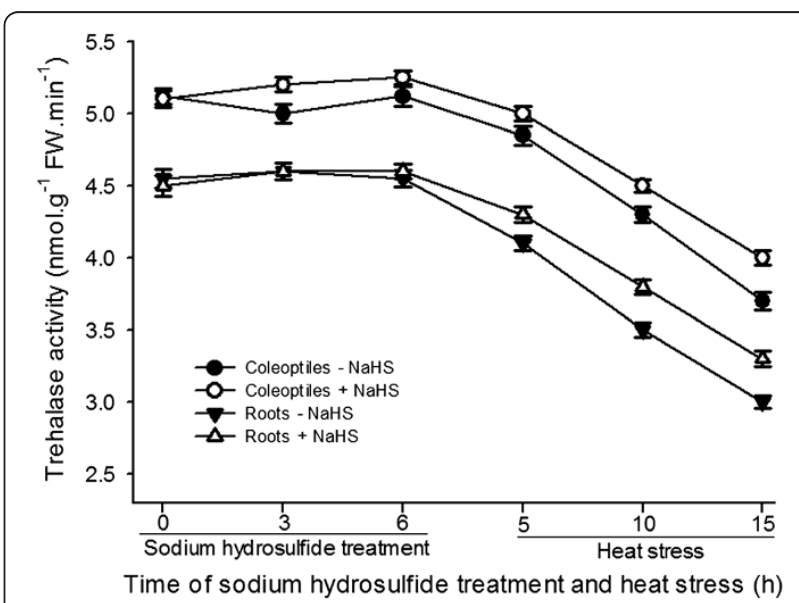

Figure 4 Effects of NaHS pretreatment on the activity of trehalase in coleoptiles and roots of maize seedlings under normal culture conditions and heat stress. Seedlings of maize were irrigated with $100 \mathrm{ml}$ of $0.6 \mathrm{mM} \mathrm{NaHS}$ for $6 \mathrm{~h}$, and then transferred to heat stress, during the treatment and heat stress, trehalase activity in both coleoptiles and roots was determined. Error bars represent standard error and each data in figure represents the mean \pm SE of three experiments. 


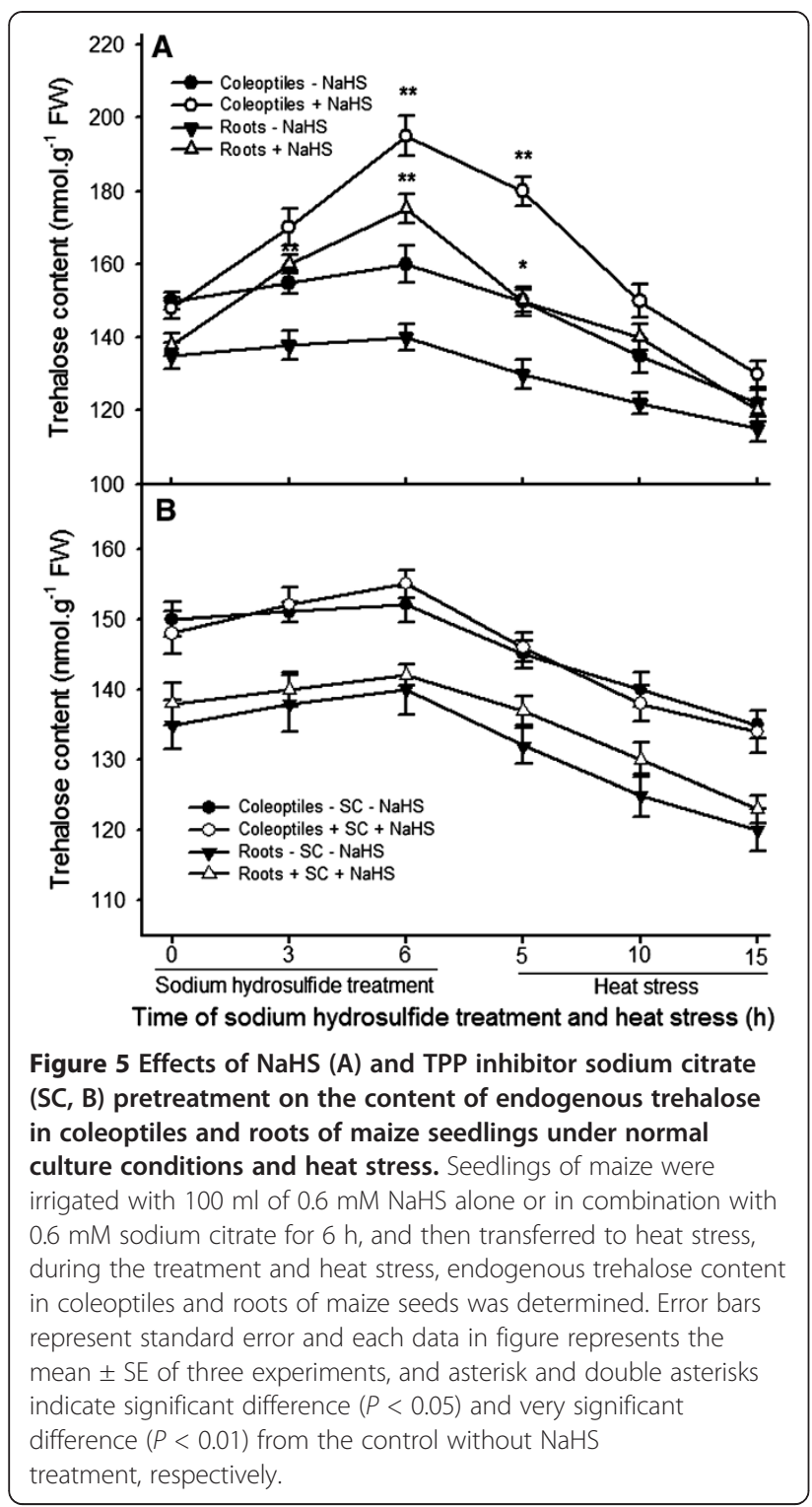

Effect of exogenous trehalose pretreatment on endogenous trehalose and $\mathrm{H}_{2} \mathrm{~S}$ contents as well as heat tolerance in maize seedlings

Pretreatment with NaHS could increase accumulation of endogenous trehalose (Figure 5A), which in turn improve heat tolerance of maize seedlings (Figures 1 and 2). To investigate effect of exogenous application of trehalose on the content of endogenous trehalose and $\mathrm{H}_{2} \mathrm{~S}$ as well as heat tolerance, endogenous trehalose and $\mathrm{H}_{2} \mathrm{~S}$ contents, electrolyte leakage, MDA content and survival percentage were determined after maize seedlings were treated with different concentration of trehalose alone or in combination with $0.6 \mathrm{mM}$ NaHS. The results indicated that exogenously applied trehalose could increase content of endogenous trehalose in coleoptiles under normal conditions (Figure 6A), and alleviated increase in electrolyte

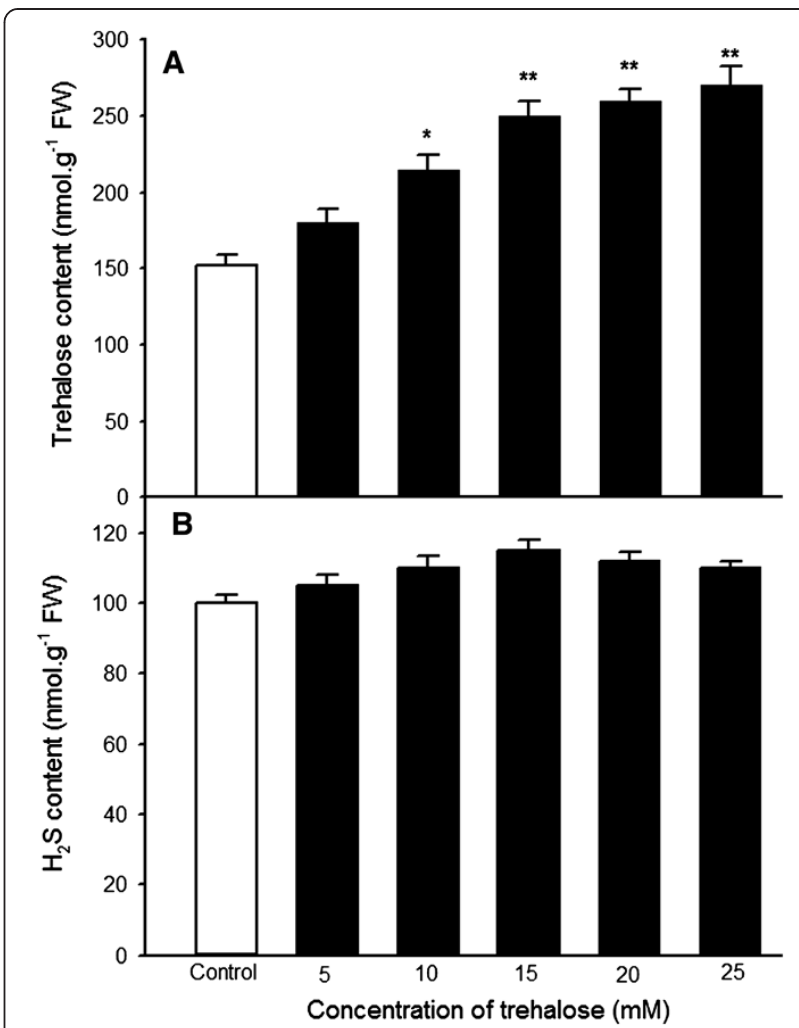

Figure 6 Effects of exogenous trehalose pretreatment on the content of endogenous trehalose (A) and $\mathrm{H}_{2} \mathrm{~S}(B)$ under normal culture conditions. Seedlings of maize were irrigated with $100 \mathrm{ml}$ of 0 (control), 5, 10, 15, 20 and $25 \mathrm{mM}$ trehalose for $6 \mathrm{~h}$, respectively, and then determined the contents of endogenous trehalose and $\mathrm{H}_{2} \mathrm{~S}$ in coleoptiles of maize seeds. Error bars represent standard error and each data in figure represents the mean \pm SE of three experiments, and asterisk and double asterisks indicate significant difference $(P<0.05)$ and very significant difference $(P<0.01)$ from the control without trehalose treatment, respectively.

leakage in roots and MDA accumulation in coleoptiles of seedlings under heat stress (Figure 7), which in turn improved survival percentage of maize seedlings (Figure 8). The content of endogenous trehalose and survival percentage improved along with the increase in concentration of exogenous trehalose (Figures 6A, and 8), while electrolyte leakage and MDA content decreased with increasing concentration of trehalose (Figure 7 ). The change in these parameters reached very significant difference $(P<0.01$, Figures 6, 7 and 8), respectively, when the concentration of exogensous trehalose was $\geq 15 \mathrm{mM}$. In addition, exogenous trehalose treatment had not significant effect on endogenous $\mathrm{H}_{2} \mathrm{~S}$ level (Figure 6B), but the heat tolerance induced by trehalose was enhanced by supplement of NaHS (Figure 8). These results displayed that pretreatment with exogenous trehalose could improve heat tolerance of maize seedlings and the acquisition of this heat tolerance was the outcome of accumulation of endogenous trehalose. 


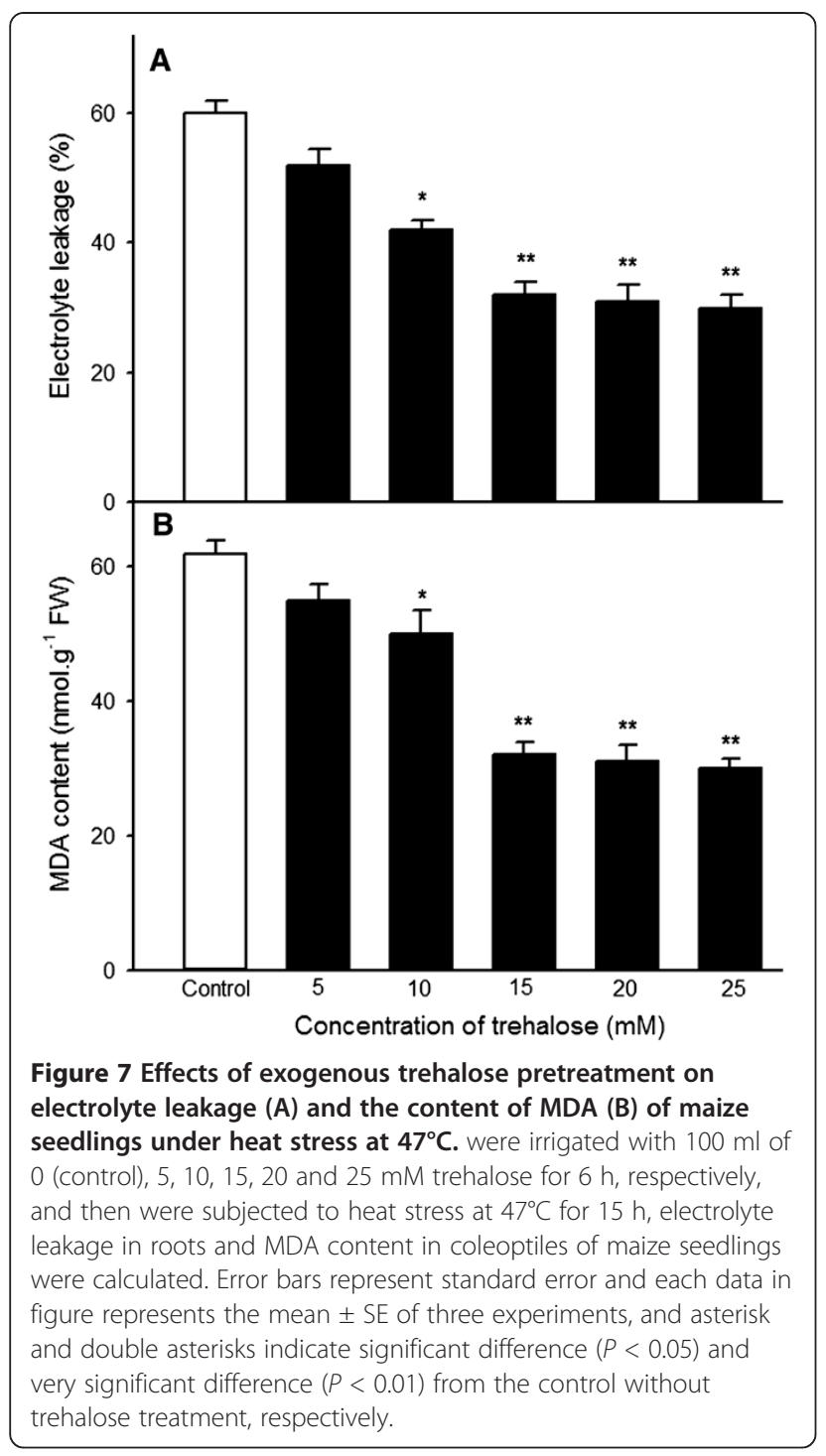

\section{Discussion}

Accumulating evidences showed that $\mathrm{H}_{2} \mathrm{~S}$ is an important signaling molecule involved in modulation of many physiological processes in plants (Mancardi et al., 2009; Zhang et al., 2010a,b; Chen et al., 2011; Wang, 2012; Li, 2013; Li et al., 2013b). In the work of (García-Mata and Lamattina 2010) displayed that $\mathrm{H}_{2} \mathrm{~S}$ participated in the abscisic acid (ABA)-dependent signalling pathway in guard cells of Vicia faba (L), which in turn induced stomatal closure, followed by protected plants against drought stress. Zhang et al. (2008; 2010a,b; 2011) found that NaHS treatment could significantly reduce MDA and $\mathrm{H}_{2} \mathrm{O}_{2}$ accumulation in wheat seeds by enhancing the activities of antioxidant enzymes catalase and ascorbate peroxidase, which in turn improved germination percentage of wheat seeds under normal conditions or multiple abiotic stress such as PEG, $\mathrm{Cu}^{2+}, \mathrm{Cr}$, and $\mathrm{Al}^{3+}$. Interestingly, in Caenorhabditis elegans, $\mathrm{H}_{2} \mathrm{~S}$ treatment can increase

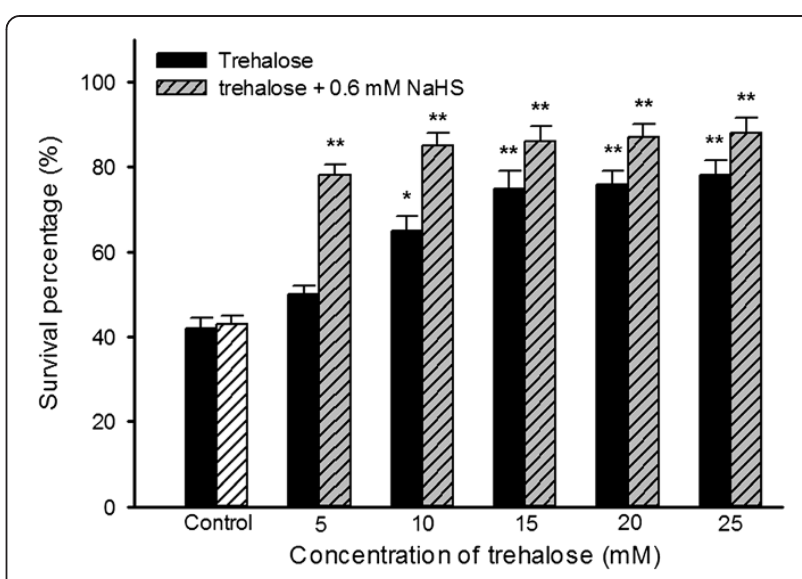

Figure 8 Effects of exogenous trehalose pretreatment alone or in combination with $0.6 \mathrm{mM}$ NaHS on survival percentage of maize seedlings under heat stress at $47^{\circ} \mathrm{C}$. Seedlings of maize were irrigated with $100 \mathrm{ml}$ of 0 (control), 5, 10, 15, 20 and $25 \mathrm{mM}$ trehalose alone or in combination with $0.6 \mathrm{mM} \mathrm{NaHS}$ for $6 \mathrm{~h}$, respectively, and then were subjected to heat stress at $47^{\circ} \mathrm{C}$ for $15 \mathrm{~h}$, the survival percentage of maize seedlings were calculated. Error bars represent standard error and each data in figure represents the mean \pm SE of three experiments, and asterisk and double asterisks indicate significant difference $(P<0.05)$ and very significant difference $(P<0.01)$ from the control without trehalose treatment, respectively.

thermotolerance and lifespan (Miller and Roth, 2007). Our previous results also found that $\mathrm{NaHS}$ pretreatment could improve heat tolerance in tobacco suspension cultured cells and wheat seedlings, and the acquisition of this heat tolerance requires the entry of extracellular $\mathrm{Ca}^{2+}$ into cells across the plasma membrane and the mediation of intracellular calmodulin (Li et al., 2012b; Wu et al., 2013). In addition, NaHS pretreatment markedly improved the activity of $\Delta^{1}$-pyrroline-5-carboxylate synthetase (P5CS) and lowered proline dehydrogenase (ProDH) activity in maize seedlings, which in turn induced the accumulation of endogenous proline, followed by improved germination percentage of seeds and survival percentage of seedlings of maize under heat stress (Li et al., 2013a), indicating that the acquisition of heat tolerance associated closely with multiple functions of proline such as maintaining integration of biomembrane and compartmentalization of organs, osmotic adjustment, redox buffering, and ROS-scavenging, inconsistent with the results of Lv et al. (2011) in Arabidopsis seedlings under heat stress. A further study observed that the acquisition of heat tolerance induced by $\mathrm{H}_{2} \mathrm{~S}$ may be required crosstalk among second messengers such $\mathrm{Ca}^{2+}$, $\mathrm{NO}, \mathrm{H}_{2} \mathrm{O}_{2}$ (Li et al., 2013b). In present study, NaHS pretreatments could increase endogenous $\mathrm{H}_{2} \mathrm{~S}$ content in maize seedlings under normal conditions, which in turn improved heat tolerance of seedlings of maize (Figures 1 and 2). All of the above-mentioned studies illustrated that pretreatment with $\mathrm{H}_{2} \mathrm{~S}$ could improve multiple stress tolerance such as heat tolerance, and the acquisition of stress 
tolerance may be involved in enhancement of antioxidant enzymes and accumulation of osmolyte proline by interactions among second messengers such $\mathrm{Ca}^{2+}, \mathrm{NO}, \mathrm{H}_{2} \mathrm{O}_{2}$, but whether the acquisition of heat tolerance of maize seedlings involved in the accumulation of trehalose is still elusive.

As mentioned above, there are two pathways of trehalose biosynthesis in higher plants, that is, the trehalose-6phosphate synthase/phosphatase (OtsA-OtsB) and the trehalase pathway, the former serves as trehalose biosynthesis, while the latter degrades it (Paul et al., 2008; Fernandez et al., 2010). Due to multiple functions of trehalose, similar to proline, such as stabilizing enzymes, proteins and lipid membranes; preventing protein aggregation; protecting biological structures; and scavenging free radical, numerous studies showed that trehalose involves in the acquisition of multiple stress tolerance (Goddijn and van Dun, 1999; Iordachescu and Imai, 2008; Paul et al., 2008; Fernandez et al., 2010). In rice seedlings, the transgenic plants with trehalose biosynthetic genes (ots $A$ and ots $B$ ) accumulate trehalose at levels $3 \sim 10$ times that of the nontransgenic controls, and this accumulation correlates with higher soluble carbohydrate levels, which in turn increased the resistance of plants to salt, drought and low-temperature stress (Garg et al., 2002). Similarly, under drought, salt and oxidative stress, TPS1 tomato plants increased trehalose biosynthesis, followed by improved tolerance than wild type (Cortina and Culiáñez-Macià, 2005). In addition, transgenic tobacco and sugarcane with trehalose synthase (Tsase) accumulated more trehalose than the control, which in turn improved the contents of water, chlorophyll $\mathrm{a}$ and $\mathrm{b}$ as well as the activity of superoxide dismutase and peroxidase, finally resulted in increased tolerance to drought and salt (Zhang et al., 2005, 2006). Luo et al. (2010) found that heat stress induced increase in endogenous trehalose, which in turn improved the resistance of winter wheat to heat stress by lowering the electrolyte leakage, content of MDA, generation of ROS, and lipoxygenase activity. In present study, pretreatment with NaHS increased the TPP activity in coleoptiles and roots of maize seedlings (Figure 3), which in turn improved the endogenous trehalose content in coleoptiles of the seedlings (Figure 5A), followed by elevated heat tolerance of maize seedlings (Figures 1 and 2), but exogenous application of NaHS had not significant effect on trehalase activity (Figure 4), indicating trehalose accumulation induced by NaHS was achieved by activating TPP. To further identify the acquisition of stress tolerance assuredly involved in trehalose, Ma et al. (2013) treated wheat callus with $50 \mathrm{mM}$ trehalose and found that pretreatment with trehalose enhanced levels of endogenous trehalose, alleviated the accumulation of MDA and the generation of ROS induced by water deficit, which in turn resulted in elevating cell viability and biomass. Additionally, exogenous application of $10 \mu \mathrm{M}$ trehalose promoted the growth in heat-stressed plants and trehalose functions downstream of ABA (Kumar et al., 2012). In present work, exogenously applied trehalose could elevate endogenous trehalose content in coleoptiles under normal conditions (Figure 6A), and alleviated increase in electrolyte leakage in roots and MDA accumulation in coleoptiles of seedlings under heat stress (Figure 7), which in turn improved survival percentage of maize seedlings (Figure 8). In addition, the heat tolerance induced by trehalose was enhanced by exogenous supplement of NaHS, whereas exogenous trehalose treatment had not significant effect on the accumulation of endogenous $\mathrm{H}_{2} \mathrm{~S}$ in maize seedlings (Figures $6 \mathrm{~B}$ and 8). These results display that trehalose may be exerted role in downstream of $\mathrm{H}_{2} \mathrm{~S}$ in the acquisition of stress tolerance including heat tolerance (Goddijn and van Dun, 1999; Benaroudj et al., 2001; Iordachescu and Imai, 2008; Luo et al., 2008; Paul et al., 2008; Fernandez et al., 2010). In present experiments, osmotic adjustment role of trehalose may be unimportant due to its lower accumulation (approximately 200 $\sim 250 \mathrm{nmol} \mathrm{g}^{-1} \mathrm{FW}$ ). Therefore, the acquisition of heat tolerance induced by NaHS in maize seedlings may be an outcome of combined action of antioxidant defense system (Zhang et al., 2008; 2010a, b; 2011) and small molecule chaperones such as proline ( $\mathrm{Li}$ et al. 2013a) and trehalose (Figures 1, 2, 3, 4, 5, 6 and 7).

\section{Conclusion}

In summary, these data suggest that sodium hydrosulfide pretreatment could improve heat tolerance of maize seedlings in a concentration-dependent manner and this improvement may be involved in trehalose accumulation by activating TPP activity.

\section{Abbreviation}

ABA: Abscisic acid; G6P: Glucose 6-phosphate; MDA: Malonaldehyde; P5CS: $\Delta^{1}$-Pyrroline-5-carboxylate synthetase; ProDH: Proline dehydrogenase; ROS: Reactive oxygen species; T6P: Trehalose 6-phosphate; TPP: Trehalose-6phosphate phosphatase; TPS: Trehalose 6-phosphate synthase; UDP: Uridine diphosphate; UDPG: Uridine diphosphate glucose.

\section{Competing interests}

The authors declare that they have no competing interests.

\section{Authors' contributions}

In this work, Z-GL carried out conception, design and writing the article, L-JL and L-PZ coordinated the study and carried out data analysis and interpretation. All authors have read and approved the final manuscript.

\section{Acknowledgements}

This research was supported by National Natural Science Foundation of China (Grant No. 31360057). We appreciate the editors and reviewers for their exceptionally helpful comments about the manuscript.

\section{Author details}

${ }^{1}$ School of Life Sciences, Yunnan Normal University, Kunming 650092, PR China. ${ }^{2}$ Engineering Research Center of Sustainable Development and Utilization of Biomass Energy, Ministry of Education, Kunming 650092, PR China. ${ }^{3}$ Key Laboratory of Biomass Energy and Environmental Biotechnology, Yunnan Province, Yunnan Normal University, Kunming 650092, PR China. 
Received: 6 December 2013 Accepted: 6 January 2014 Published: 3 February 2014

\section{References}

Benaroudj N, Lee DH, Goldberg AL (2001) Trehalose accumulation during cellular stress protects cells and cellular proteins from damage by oxygen radicals. J Biol Chem 276:24261-24267

Chen J, Wu FH, Wang WH, Zheng CJ, Lin GH, Dong XJ, He JX, Pei ZM, Zheng H (2011) Hydrogen sulphide enhances photosynthesis through promoting chloroplast biogenesis, photosynthetic enzyme expression, and thiol redox modification in Spinacia oleracea seedlings. J Exp Bot 62:4481-4493

Christou A, Manganaris GA, Papadopoulos I, Fotopoulos V (2013) Hydrogen sulfide induces systemic tolerance to salinity and non-ionic osmotic stress in strawberry plants through modification of reactive species biosynthesis and transcriptional regulation of multiple defence pathways. J Exp Bot 64:1953-1966

Cortina C, Culiáñez-Macià FA (2005) Tomato abiotic stress enhanced tolerance by trehalose biosynthesis. Plant Sci 169:75-82

El-Bashiti T, Hamamcl H, Öktem HA, Yücel M (2005) Biochemical analysis of trehalose and its metabolizing enzymes in wheat under abiotic stress conditions. Plant Sci 169:47-54

Fernandez O, Béthencourt L, Quero A, Sangwan RS, Clément C (2010) Trehalose and plant stress responses: friend or foe? Trends Plant Sci 15:409-417

García-Mata C, Lamattina L (2010) Hydrogen sulphide, a novel gasotransmitter involved in guard cell signaling. New Phytol 188:977-984

García-Mata C, Lamattina L (2013) Gasotransmitters are emerging as new guard cell signaling molecules and regulators of leaf gas exchange. Plant Sci 201 (202):66-73

Garg N, Chandel S (2011) The effects of salinity on nitrogen fixation and trehalose metabolism in mycorrhizal Cajanus cajan (L.) millsp. plants. J Plant Growth Regul 30:490-503

Garg AK, Kim JK, Owens TG, Ranwala AP, Choi YD, Kochian LV, Wu RJ (2002) Trehalose accumulation in rice plants confers high tolerance levels to different abiotic stresses. Proc Natl Acad Sci U S A 99:15898-15903

Goddijn OJ, van Dun K (1999) Trehalose metabolism in plants. Trends Plant Sci 4:315-319

Hancock JT, Lisjak M, Teklic T, Wilson ID, Whiteman M (2011) Hydrogen sulphide and signalling in plants. CAB Rev: Perspect Agric Vet Sci Nutr Nat Resour 6:1-7

Hanumappa M, Nguyen HT (2010) Genetic approaches toward improving heat tolerance in plants. In: Jenks MA, Wood AJ (eds) Genes for plant abiotic stress. Wiley-Blackwell, Oxford, pp 221-260

lordachescu M, Imai R (2008) Trehalose biosynthesis in response to abiotic stresses. J Integr Plant Biol 50:1223-1229

Jagdale GB, Grewal PS (2003) Acclimation of entomopathogenic nematodes to novel temperatures: trehalose accumulation and the acquisition of thermotolerance. Int J Parasitol 33:145-152

Kumar S, Kaushal N, Nayyar H, Gaur P (2012) Abscisic acid induces heat tolerance in chickpea (Cicer arietinum L.) seedlings by facilitated accumulation of osmoprotectants. Acta Physiol Plant 34:1651-1658

Leipner J, Stamp P (2009) Chilling Stress in Maize Seedlings. In: Bennetzen JL, Hake SC (eds) Handbook of Maize: Its Biology. Springer, Heidelberg, pp 291-344

Li ZG (2013) Hydrogen sulfide: a multifunctional gaseous molecule in plants. Russ J Plant Physiol 60:733-740

Li L, Rose P, Moore PK (2011) Hydrogen sulfide and cell signaling. Annu Rev Pharmacol Toxicol 51:169-187

Li ZG, Gong M, Liu P (2012a) Hydrogen sulfide is a mediator in $\mathrm{H}_{2} \mathrm{O}_{2}$-induced seed germination in Jatropha Curcas. Acta Physiol Plant 34:2207-2213

Li ZG, Gong M, Xie H, Yang L, Li J (2012b) Hydrogen sulfide donor sodium hydrosulfide-induced heat tolerance in tobacco (Nicotiana tabacum L.) suspension cultured cells and involvement of $\mathrm{Ca} 2+$ and calmodulin. Plant Sci 185:185-189

Li ZG, Ding XJ, Du PF (2013a) Hydrogen sulfide donor sodium hydrosulfideimproved heat tolerance in maize and involvement of proline. J Plant Physiol 170:741-747

Li ZG, Yang SZ, Long WB, Yang GX, Shen ZZ (2013b) Hydrogen sulfide may be a novel downstream signal molecule in nitric oxide-induced heat tolerance of maize (Zea mays L.) seedlings. Plant Cell Environ 36:1564-1572

Lisjak M, Srivastava N, Teklic T, Civale L, Lewandowski K, Wilson I, Wood ME, Whiteman M, Hancock JT (2010) A novel hydrogen sulfide donor causes stomatal opening and reduces nitric oxide accumulation. Plant Physiol Biochem 48:931-935
Lisjak M, Teklic T, Wilson ID, Whiteman M, Hancock JT (2013) Hydrogen sulfide: environmental factor or signalling molecule? Plant Cell Environ 36:1607-1616

Lunn JE, Feil R, Hendriks JHM, Gibon Y, Morcuende R, Osuna D, Scheible WR, Carillo P, Hajirezaei MR, Stitt M (2006) Sugar-induced increases in trehalose 6-phosphate are correlated with redox activation of ADPglucose pyrophosphorylase and higher rates of starch synthesis in Arabidopsis thaliana. Biochem J 397:139-148

Luo Y, Li WM, Wang W (2008) Trehalose: protector of antioxidant enzymes or reactive oxygen species scavenger under heat stress? Environ Exp Bot 63:378-384

Luo Y, Li F, Wang GP, Yang XH, Wang W (2010) Exogenously-supplied trehalose protects thylakoid membranes of winter wheat from heat-induced damage. Biol Plant 54:495-501

Lv WT, Lin B, Zhang M, Hua XJ (2011) Proline accumulation is inhibitory to arabidopsis seedlings during heat stress. Plant Physiol 56:1921-1933

Ma C, Wang Z, Kong B, Lin T (2013) Exogenous trehalose differentially modulate antioxidant defense system in wheat callus during water deficit and subsequent recovery. Plant Growth Regul 70:275-285

Mancardi D, Penna C, Merlino A, Soldato PD, Wink DA, Pagliaro P (2009) Physiological and pharmacological features of the novel gasotransmitter: hydrogen sulfide. Biochim Biophys Acta 1787:864-872

Miller DL, Roth MB (2007) Hydrogen sulfide increases thermotolerance and lifespan in Caenorhabditis elegans. Proc Natl Acad Sci U S A 104:20618-20622

Paul MJ, Primavesi LF, Jhurreea D, Zhang Y (2008) Trehalose metabolism and signaling. Annu Rev Plant Biol 59:417-441

Shan CJ, Zhang SL, Li DF, Zhao YZ, Tian XL, Zhao XL, Wu YX, Wei XY, Liu RQ (2011) Effects of exogenous hydrogen sulfide on the ascorbate and glutathione metabolism in wheat seedlings leaves under water stress. Acta Physiol Plant 33:2533-2540

Strable J, Scanlon MJ (2009) Maize (Zea Mays): a model organism for basic and applied research in plant biology. Cold Spring Harb Protoc 10(2009):pdb.emo132

Wahid A, Gelani S, Ashraf M, Foolad MR (2007) Heat tolerance in plants: an overview. Environ Exp Bot 61:199-223

Wang R (2012) Physiological implications of hydrogen sulfide: a whiff exploration that blossomed. Physiol Rev 92:791-896

Wu DH, Li YL, Xia X, Pu ZP, Liao JM, Huang K, Li ZG (2013) Hydrogen sulfide donor sodium hydrosulfide pretreatment improved multiple resistance abilities of wheat to high temperature and drought Stress. J Yunnan Norm Univ Nat Sci 33:29-35

Zhang SZ, Yang BP, Feng CL, Tang H (2005) Genetic transformation of tobacco with the trehalose synthase gene fromGrifola frondosa Fr. Enhances the resistance to drought and salt in tobacco. J Integr Plant Biol 47:579-587

Zhang SZ, Yang BP, Feng CL, Chen RK, Luo JP, Cai WW, Liu FH (2006) Expression of the grifola frondosa trehalose synthase gene and improvement of drought-tolerance in sugarcane (saccharum officinarum L.). J Integr Plant Biol 48:453-459

Zhang H, Hu LY, Hu KD, He YD, Wang SH, Luo JP (2008) Hydrogen sulfide promotes wheat seed germination and alleviates oxidative damage against copper stress. J Integr Plant Biol 50:1518-1529

Zhang $H$, Tang J, Liu XP, Wang Y, Yu W, Peng WY, Fang F, Ma DF, Wei ZJ, Hu LY (2009a) Hydrogen sulfide promotes root organogenesis in Ipomoea batatas, Salix matsudana and Glycine max. J Integr Plant Biol 51:1084-1092

Zhang H, Ye YK, Wang SH, Luo JP, Tang J, Ma DF (2009b) Hydrogen sulfide counteracts chlorophyll loss in sweet potato seedling leaves and alleviates oxidative damage against osmotic stress. Plant Growth Regul 58:243-250

Zhang H, Hu LY, Li P, Hu KD, Jiang CX, Luo JP (2010a) Hydrogen sulfide alleviated chromium toxicity in wheat. Biol Plant 54:743-747

Zhang H, Wang MF, Hua LY, Wang SH, Hua KD, Bao LJ, Luo JP (2010b) Hydrogen sulfide promotes wheat seed germination under osmotic stress. Russ J Plant Physiol 57:532-539

Zhang H, Hua SL, Zhang ZJ, Hua LY, Jiang CX, Wei ZJ, Liu J, Wang HL, Jiang ST (2011) Hydrogen sulfide acts as a regulator of flower senescence in plants. Postharv Biol Technol 60:251-257

Zhou ML, Zhang Q, Sun ZM, Chen LH, Liu BX, Zhang KX, Zhu XM, Shao JR, Tang YX, Wu YM (2013) Trehalose metabolism-related genes in maize. J Plant Growth Regul, doi: 10.1007/s00344-013-9368-y. In press

\section{doi:10.1186/1999-3110-55-20}

Cite this article as: Li et al.: Involvement of trehalose in hydrogen sulfide donor sodium hydrosulfide-induced the acquisition of heat tolerance in maize (Zea mays L.) seedlings. Botanical Studies 2014 55:20. 